\title{
Long-Term Dynamics of Urban Soil Pollution with Heavy Metals in Moscow
}

\author{
N. E. Kosheleva and E. M. Nikiforova \\ Faculty of Geography, Moscow State University, Leninskie Gory, Moscow 119991, Russia \\ Correspondence should be addressed to N. E. Kosheleva; natalk@mail.ru
}

Received 2 October 2015; Revised 17 December 2015; Accepted 22 December 2015

Academic Editor: Francesco Sdao

Copyright (c) 2016 N. E. Kosheleva and E. M. Nikiforova. This is an open access article distributed under the Creative Commons Attribution License, which permits unrestricted use, distribution, and reproduction in any medium, provided the original work is properly cited.

\begin{abstract}
Results of 21-year-long (1989-2010) observations of the concentrations and the spatial distribution patterns of nine heavy metals (HMs) in topsoils of the Eastern district of Moscow are presented. The quantitative parameters of soil pollution include the annual increase rates of $\mathrm{HM}$ concentrations in several land-use zones. The maps of geochemical anomalies were compiled using the data collected in 1989, 2005, and 2010. The growth of the total volume of industrial and vehicles' emissions between 1989 and 2005 caused significant deposition of $\mathrm{Pb}, \mathrm{Zn}, \mathrm{Cu}$, and $\mathrm{Cd}$. The additional input of $\mathrm{Cd}$ to the soils is attributed to the application of sewage sludge as fertilizers. The relative increment of concentrations was the highest for $\mathrm{Pb}, \mathrm{Co}, \mathrm{Cu}, \mathrm{Ni}$, and $\mathrm{Cr}$. In 2005-2010, the relative annual increment rate was the highest for $\mathrm{Cr}, \mathrm{Cd}, \mathrm{Co}$, and $\mathrm{Ni}$, and it increased by an order of magnitude as compared to the previous period. By contrast, $\mathrm{Pb}$ and $\mathrm{Cu}$ concentrations decreased owing to the soil reclamation, the exclusion of leaded gasoline as a fuel for vehicles and closing some hazardous enterprises. Joint analysis of snow and soil geochemical maps allows identification of the zones of actual, permanent, and relict pollution.
\end{abstract}

\section{Introduction}

Development of industrial cities and rapid growth of urban population aggravates ecological problems caused by air and water contamination and permanent accumulation of pollutants in soils. Heavy metals (HMs) are of special concern since they belong to very hazardous substances. The content and distribution of HMs in Moscow soils have been analyzed by many authors [1-7]. At the same time, such urgent issues of urban ecology as a long-term dynamics of soil contamination with HMs in different land-use zones have not yet been considered. The aim of this research is to study spatialtemporal trends in soil contamination with HMs in one of the most polluted districts of Moscow.

The specific purposes of the study are as follows:

(i) to investigate the main features of long-term dynamics of HM content in the soil cover in relation to landuse type and fluctuations in urban activities;

(ii) to map technogenic geochemical anomalies in urban soils for different time periods; (iii) to determine the character and intensity of $\mathrm{HM}$ accumulation in urban soils by combined analysis of snow and soil geochemical maps;

(iv) to evaluate the environmental risk of the contamination on the basis of integral indices.

\section{Materials and Methods}

The Eastern district has been chosen as a study object; it is located on the Meshchera outwash plain. The southern, most polluted, part of the Moscow Eastern district was investigated. This territory belongs to the southern taiga Meshchera landscapes with a temperate continental climate. The snow cover appears in late October-early January and reaches the maximum height in February-March. A flat plain with altitudes of 150-160 $\mathrm{m}$ a.s.l. is composed of glaciofluvial sands and loams with low content of HMs [8]. Soil cover has been severely disturbed; natural sod-podzolic, podzolicbog, and bog soils are preserved only locally in the suburbs and green areas. The major part of the area is occupied by 

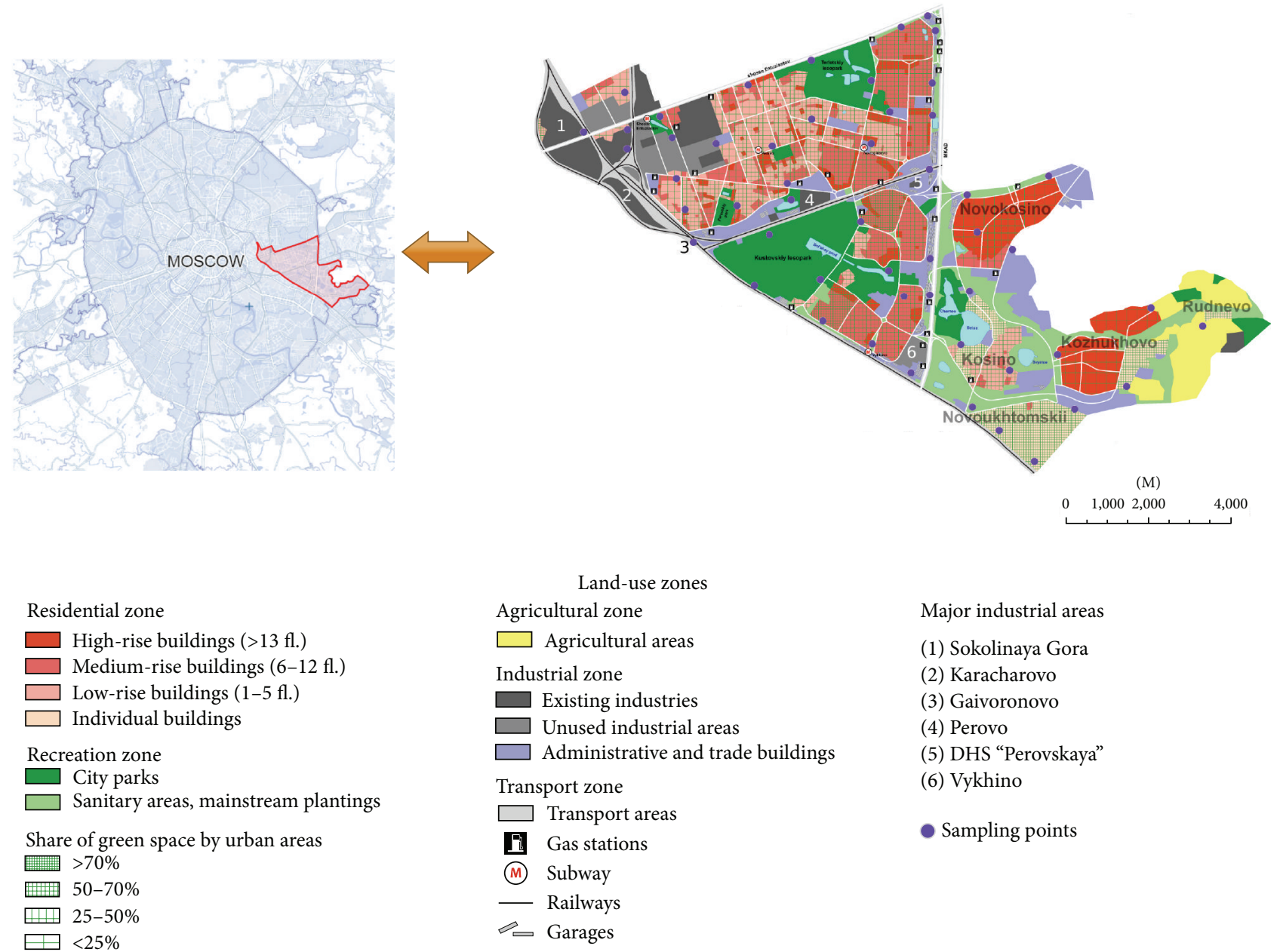

Land-use zones
Agricultural zone
$\square$ Agricultural areas
Industrial zone
Existing industries
Unused industrial areas
Administrative and trade buildings
Transport zone
$\square$ Transport areas
G Gas stations
$\square$ Subway
$\square$ Railways

Major industrial areas

(1) Sokolinaya Gora

(2) Karacharovo

(3) Gaivoronovo

(4) Perovo

(5) DHS "Perovskaya"

(6) Vykhino

- Sampling points

FIgURE 1: The map of land-use zones for the territory of the Eastern district of Moscow [12].

specific urban soils, that is, urbanozems and technozems [9], developed on filled redeposited substrates and the cultivated layer; in some parks and recreation zones, soils develop on the natural parent rocks.

The most widespread soils are urbanozems that are deeply transformed anthropogenic soils, the profiles of which change to a depth of more than $50 \mathrm{~cm}$. Their main difference from natural soils is the presence of a diagnostic "urbic" horizon. This surface horizon is a filled mixed layer with an admixture $(>5 \%)$ of anthropogenic inclusions (construction and industrial waste, domestic garbage); as a rule, it contains organic matter. The physical and chemical properties of this horizon change owing to the input of eolian dust [5].

The territory has multispecialized industries, including instruments and equipment producing, chemical and oilprocessing factories, heating power stations, incineration plant, and a dense network of roads. Highways are the Moscow Ring Road (MKAD) and Shosse Entuziastov. Motor transport is the main source of pollution in the district [10]. The largest industrial zones are Karacharovo and Sokolinaya Gora in the north-east of the study area; Perovo in the center; Vykhino and Gaivoronovo in the south. Owing to the fall in production and decrease in the volume of wastes and emissions, the input of stationary air pollution sources decreased from $26-27 \%$ of the total mass of technogenic load, in the early 1990 s to $10 \%$ at the end of the decade [11]. Nevertheless Moscow still ranks 10th-13th among Russian cities by the total pollution level from stationary sources; industry remains the most important factor responsible for the contamination of the urban environment with specific emissions.

The geochemical studies and soil sampling were performed during the summers of 1989, 2005, and 2010 at the same points (Figure 1). Samples were collected at approximately uniform grid with a sampling spacing of 700-900 m. This scheme is widely used in the world for geochemical mapping of cities [13]. Altogether 153 soil mixed samples were taken from the most humus enriched and contaminated upper $(0$ to $15 \mathrm{~cm}$ ) horizons of the urban soils. Mixed samples were composed of 4 individual ones. Soddy-podzolic soils of the Meshchera Plain (45-50 km east of the city, where its influence was not displayed) were studied as background analogues. These light-textured soils develop under meadow grass-forb and forest spruce-birch communities. Ten samples 
TABLE 1: Levels of landscape pollution with HMs and dust [14].

\begin{tabular}{lcccc}
\hline $\begin{array}{l}\text { Levels of } \\
\text { pollution }\end{array}$ & $\begin{array}{c}\text { Dust deposition } \\
P_{n}, \mathrm{~kg} / \mathrm{km}^{2} \text { per day }\end{array}$ & HM immission $Z_{d}$ & $\begin{array}{c}\text { Total indices of } \\
\text { Snow pollution } Z_{c}\end{array}$ & Soil pollution $Z_{c}$ \\
\hline Low & $<200$ & $<1000$ & $<32$ & $<16$ \\
Medium & $200-300$ & $1000-2000$ & $32-64$ & $16-32$ \\
High & $300-500$ & $2000-4000$ & $64-128$ & $32-64$ \\
Very high & $500-800$ & $4000-8000$ & $128-256$ & $64-128$ \\
Maximum & $>800$ & $>8000$ & $>256$ & $>128$ \\
\hline
\end{tabular}

were taken from the surface horizons of the reference soils. The bulk content of $\mathrm{Zn}, \mathrm{Cd}, \mathrm{Pb}, \mathrm{Cu}, \mathrm{Cr}, \mathrm{Co}, \mathrm{Ni}, \mathrm{Mn}$, and $\mathrm{Cs}$ was determined by atomic absorption spectrometry using an Hitachi 180-70 spectrometer. To determine all the elements soil samples were transferred into the state of the solution using the mixture of acids $\mathrm{HCl}, \mathrm{HClO}_{4}$, and $\mathrm{HNO}_{3}$, with triple evaporation and complexation of HF with boric acid. The residue was then dissolved in $\mathrm{HCl}$.

The type of land use is of primary importance for the formation of technogenic geochemical anomalies; therefore land-use zoning of the territory was performed using satellite high-resolution images [12]. The following areas were specified (Figure 1): highways and industrial zones, mediumrise residential blocks within MKAD, recreation zone (parks, forest parks, and leisure areas), new high-rise buildings (Novokosino, Kozhukhovo), old residential blocks (private low-rise buildings in Novoukhtomskii, Kosino, and Rudnevo settlements), and agricultural area (arable lands of the former Mossovet sovkhoz). The zones differ in duration and intensity of anthropogenic stress. Geochemical maps were compiled using spline interpolation (Geostatistical Analyst, ArcGIS 10).

The accumulation or dispersion of dust and HMs in urban soils was evaluated using enrichment or depletion factors estimated via comparison with the data on the HM concentrations $C f$ in the reference soddy-podzolic soils: $\mathrm{EF}=C / C f$ and $\mathrm{DF}=C f / C$, where $C$ is the element concentration in urban soils. The results are displayed on a special plot named geochemical spectrum. The immission of the solid fraction of HMs to soil $D$ equals the dust load $P_{n}$ in the snow multiplied by HM concentration in it; $D=P_{n}$. C. Exceedance of HM fallout above background values $D f$ is characterized by a factor $K_{d}=D / D f$. Total multielemental pollution of snow and soil cover is defined by integral indices of immission $Z_{d}=\sum_{i=1}^{n} K_{d}-(n-1)$ and total pollution $Z_{c}=\sum_{i=1}^{n} \mathrm{EF}-(n-1)$, respectively, where $n$ is number of elements with $K_{d}$ or EF > 1. They summarize the excess of the HM contents in urban soils over background levels and thus display the degree of their anthropogenic geochemical transformation $[14,25,26]$. Integral indices have 5 levels which determine the degree of pollution (Table 1). Maps of these parameters reveal spatial patterns of pollution in these depositing media.

\section{Results and Discussion}

3.1. Accumulation of HMs in Urban Soils. The intensity of HM accumulation in the soils of the Eastern district (Figure 2) was evaluated in relation to the background soils

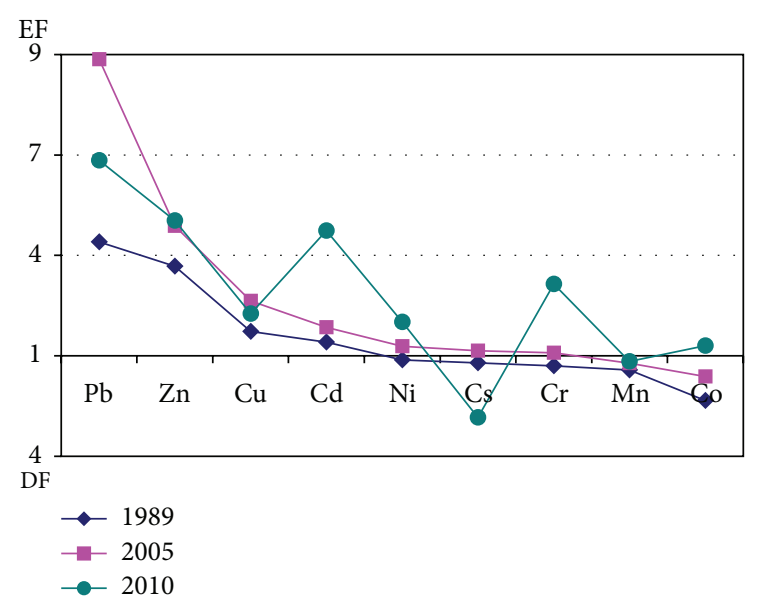

FIGURE 2: Geochemical spectra of urban soils in the Eastern district of Moscow showing enrichment and depletion factors (EF, DF) of metals in relation to background soils.

of Meshchera plain which have trace-level concentrations of all HMs under study, except for Cd and Cs. Low values of metal concentrations in background soils are explained by their contents in parent fluvioglacial sands [8] and the small intensity of fallout from the atmosphere [2, 9].

In 1989 the group of four elements accumulated in urban soils with the following sequence according to their enrichment factors $\mathrm{EF}$ (inferior indices): $\mathrm{Pb}_{4.4} \mathrm{Zn}_{3.7} \mathrm{Cu}_{1.7} \mathrm{Cd}_{1.4}$. Other metals dissipated with intensity which was defined by their depletion factors DF (top indices): $\mathrm{Co}^{2.3} \mathrm{Mn}^{1.4} \mathrm{Cr}^{1.3} \mathrm{Cs}^{1.2} \mathrm{Ni}^{1.1}$. The content of HMs in urban soils was very variable; coefficients of variation $\mathrm{CV}$ of particular HMs changed from 41 to $89 \%$, reaching $102 \%$ for Cd because of differences between the individual land-use zones.

In 2005 metals pollutants showed the increasing content while preserving the above sequence: $\mathrm{Pb}_{9.9} \mathrm{Zn}_{4.9} \mathrm{Cu}_{2.6} \mathrm{Cd}_{1.8}$. During 1989-2005 the average concentrations of two main pollutants, $\mathrm{Pb}$ and $\mathrm{Zn}$, increased by a factor of 2.2 and 1.3 , respectively. The content of $\mathrm{Cr}$, $\mathrm{Cs}$, and $\mathrm{Ni}$ came close to their background levels; only Co and $\mathrm{Mn}$ had concentrations below the background values (DF 1.6 and 1.2). Soil concentrations of all HMs under study were slightly less variable than in 1989 (CV 32-66\% for Co, Ni, Mn, Cs, Zn, Cr, and $\mathrm{Cu}$ and $91-92 \%$ for $\mathrm{Cd}$ and $\mathrm{Pb}$ ).

In 2010, 21 years after the beginning of investigations, further growth of soil pollution with HMs was observed, and 
TABLE 2: Mean content of HMs ( $\mathrm{mg} / \mathrm{kg}$ ) in topsoils of natural background and various land-use zones in the Eastern district of Moscow in 1989, 2005, and 2010.

\begin{tabular}{|c|c|c|c|c|c|c|c|c|c|}
\hline Year (number of samples) & $\mathrm{Pb}$ & $\mathrm{Zn}$ & $\mathrm{Cu}$ & $\mathrm{Cd}$ & Co & $\mathrm{Cr}$ & $\mathrm{Ni}$ & $\mathrm{Mn}$ & Cs \\
\hline \multicolumn{10}{|c|}{ Natural background of the Meshchera lowland } \\
\hline $1989(10)$ & 9.04 & 37.5 & 27.9 & 0.34 & 6.60 & 32.0 & 15.2 & 585 & 5.40 \\
\hline \multicolumn{10}{|c|}{ Highways (A) and industrial zones (P) } \\
\hline $1989(12)$ & 60.5 & 224 & 80.7 & 0.65 & 3.85 & 34.0 & 17.6 & 442 & 5.58 \\
\hline $2005(14)$ & 174 & 305 & 130 & 0.81 & 5.82 & 51.7 & 26.9 & 518 & 8.08 \\
\hline 2010 (13), A & 59.5 & 183 & 67.5 & 1.23 & 8.48 & 89.9 & 32.2 & 412 & 1.90 \\
\hline $2010(5), \mathrm{P}$ & 114 & 286 & 88.0 & 1.37 & 9.3 & 92.2 & 35.4 & 513 & 1.88 \\
\hline \multicolumn{10}{|c|}{ Residential zone with low-rise buildings (L) } \\
\hline $1989(5)$ & 72.4 & 138 & 39.4 & 0.64 & 2.67 & 32.1 & 16.2 & 463 & 4.53 \\
\hline $2005(5)$ & 159 & 180 & 65.7 & 0.81 & 3.84 & 47.9 & 22.6 & 549 & 6.34 \\
\hline $2010(5)$ & 68.8 & 163 & 60.6 & 1.33 & 8.12 & 95.6 & 33.6 & 544 & 1.64 \\
\hline \multicolumn{10}{|c|}{ Residential zone with medium-rise buildings (M) } \\
\hline $1989(16)$ & 23.4 & 130 & 40.1 & 0.35 & 2.48 & 20.5 & 12.1 & 340 & 4.65 \\
\hline $2005(17)$ & 39.9 & 165 & 58.8 & 0.48 & 3.76 & 29.2 & 17.8 & 414 & 6.47 \\
\hline $2010(10)$ & 66.7 & 223 & 62.3 & 1.43 & 8.6 & 106 & 30.0 & 493 & 2.09 \\
\hline \multicolumn{10}{|c|}{ Residential zone with high-rise buildings $(\mathrm{H})$} \\
\hline $1989(5)$ & 16.4 & 76.5 & 24.6 & 0.14 & 1.61 & 16.3 & 9.14 & 260 & 2.43 \\
\hline $2005(5)$ & 20.2 & 88.3 & 28.1 & 0.15 & 1.82 & 18.2 & 10.6 & 309 & 2.91 \\
\hline $2010(7)$ & 44.1 & 162 & 54.0 & 1.45 & 8.57 & 104 & 26.1 & 389 & 1.99 \\
\hline \multicolumn{10}{|c|}{ Recreational zone (R) } \\
\hline $1989(6)$ & 21.1 & 76.7 & 24.3 & 0.17 & 2.44 & 9.24 & 7.58 & 512 & 4.04 \\
\hline $2005(6)$ & 32.9 & 82.7 & 28.9 & 0.20 & 2.87 & 11.6 & 9.20 & 538 & 4.44 \\
\hline $2010(9)$ & 49.4 & 147 & 50.4 & 2.05 & 8.8 & 101 & 29.0 & 482 & 1.87 \\
\hline \multicolumn{10}{|c|}{ Agricultural landscapes (AG) } \\
\hline $1989(5)$ & 45.6 & 96.3 & 57.7 & 1.07 & 3.20 & 34.0 & 18.0 & 535 & 3.74 \\
\hline $2005(5)$ & 84.7 & 122 & 71.2 & 1.44 & 4.09 & 37.9 & 21.5 & 640 & 5.19 \\
\hline $2010(3)$ & 34.0 & 173 & 67.0 & 3.70 & 7.7 & 137 & 27.3 & 492 & 1.47 \\
\hline
\end{tabular}

the group of metals concentrated in topsoils was expanded up to seven elements. According to EF values, they form the following sequence: $\mathrm{Pb}_{6.8} \mathrm{Zn}_{5.0} \mathrm{Cd}_{4.7} \mathrm{Cr}_{3.1} \mathrm{Cu}_{2.3} \mathrm{Ni}_{2.0} \mathrm{Co}_{1.3}$. $\mathrm{Mn}$ and $\mathrm{Cs}$ have the contents below background (DF 1.2 and 2.8 , resp.). Since Cs is concentrated in hydroxides of $\mathrm{Mn}$, its removal (washout) from the topsoils is accompanied by a significant decrease in the content of Cs [27]. The concentration of $\mathrm{Pb}$ - the main pollutant-decreased by a factor of 1.4 in comparison to 2005 that could be the result of soil reclamation in combination with the exclusion of leaded gasoline as a fuel for vehicles and the closing some hazardous enterprises which produced machines and electronic equipment. The intensive growth of Cd content in urban soils is caused by its presence in the motor vehicle emissions; in agricultural and recreation zone it is related to the application of large amounts of mineral and organic fertilizers and sewage sludge which contain $\mathrm{Cd}$ as an admixture. Concentrations of other metals increased slightly or remained at the same level. The contents of $\mathrm{Co}, \mathrm{Cs}$, and $\mathrm{Pb}$ in soils became less variable, while that of $\mathrm{Zn}$ and $\mathrm{Cr}$ increased up to $68-70 \%$ and of $\mathrm{Cd}$, up to $136 \%$.

3.2. HM Content in Soils with Different Type of Land Use. Distinctions in the levels of HM concentration in soils of different land-use zones were revealed through the analysis of values in Table 2. Differences in mean HM content were evaluated by $t$-test. They were significant at P $90-95 \%$ for the majority of the elements and land-use zones since mixed samples which were composed of 4 individual ones were used. In $1989 \mathrm{~Pb}$ and $\mathrm{Zn}$ were accumulated in soils of all land-use zones, particularly within old low-rise residential areas (EF 8.0 and 3.7, resp.), near highways (6.7 and 6.0), and agricultural areas (5.0 and 2.6). The third priority pollutant$\mathrm{Cu}$-was mostly accumulated in the industrial and transport zones (2.9). Soils of the recreational zone and new high-rise residential areas showed low contents of HMs. Among them the greatest dispersion of Cr (DF 3.5 and 2.0) and Co (2.7 and 4.1, resp.) in comparison with background soils was observed.

In 2005 the overall picture of HMs distribution in the soils of individual zones was the same, but the concentrations of main pollutants $-\mathrm{Pb}$ and $\mathrm{Zn}-$ significantly increased (Table 2). The highest concentrations were found in the soils of highways and industrial zone (EF 19.2 and 8.1, resp.), old residential blocks (17.6 and 4.8), and agricultural areas (9.4 and 3.3). Low concentrations of the majority of HMs (Co, Cr, $\mathrm{Cd}, \mathrm{Ni}, \mathrm{Mn}$, and $\mathrm{Cs}$ ) in comparison with background values 
TABLE 3: Mean surplus/decrease rate of HM contents in topsoils of the Eastern district of Moscow.

\begin{tabular}{lccccccccccc}
\hline Period & Increment rate & $\mathrm{Pb}$ & $\mathrm{Zn}$ & $\mathrm{Cu}$ & $\mathrm{Cd}$ & $\mathrm{Co}$ & $\mathrm{Cr}$ & $\mathrm{Ni}$ & $\mathrm{Mn}$ & $\mathrm{Cs}$ \\
\hline \multirow{2}{*}{$1989-2005$} & $\mathrm{mg} / \mathrm{kg}$ per year & 3.1 & 2.8 & 1.6 & 0.01 & 0.08 & 0.64 & 0.36 & 4.40 & 0.11 \\
& $\%$ & 0.08 & 0.03 & 0.04 & 0.03 & 0.04 & 0.03 & 0.03 & 0.02 & 0.03 \\
\hline \multirow{2}{*}{$1989-2005$} & $\mathrm{mg} /$ kg per year & -5.4 & 1.2 & -2.1 & 0.20 & 0.90 & 13.0 & 2.2 & 3.8 & -0.86 \\
& $\%$ & -0.36 & 0.03 & -0.15 & 0.89 & 0.71 & 0.97 & 0.45 & 0.04 & -1.1 \\
\hline
\end{tabular}

were observed in the soils of recreational zone and new highrise residential quarters (DF 3.6-1.1).

In 2010 geochemical contrasts in the soils of individual land-use zones became less pronounced. The concentrations of $\mathrm{Cr}, \mathrm{Co}$, and $\mathrm{Mn}$ increased in comparison with 2005 practically in all land-use zones, and those of $\mathrm{Pb}, \mathrm{Cu}, \mathrm{Zn}$ decreased in transport and industrial zones, old residential and agricultural areas (except for $\mathrm{Zn}$ ). The content of $\mathrm{Pb}$ in these zones decreased by a factor of 2.3-2.5 that is apparently related to the soil reclamation, as well as to improvement of fuel and changes of vehicle structure. The content of $\mathrm{Cd}$ sharply increased, especially in the soils of recreational and agricultural zones. This could be explained by the application of high doses of sewage sludge and phosphoric fertilizers.

\subsection{Long-Term Dynamics of HM Anomalies in Urban Soils.} The time-spatial patterns of HMs distribution in soils are presented on the maps of $Z_{c}$ index compiled for several years of the 21-year-long period of observations (Figure 3). In 1989 the territory was characterized by low level of total pollution $\left(Z_{c}<16\right)$ as a result of rather weak industrial and transport influence on urban soils. On this background there were several small spots of low-contrast technogenic anomalies of HMs with medium level of pollution located in northwest, southeast, and central parts of the district. In the centers of these anomalies the values of $Z_{c}$ indicator did not exceed 3235.

In 2005 the existing anomalies of HMs in soil cover of the district considerably increased their size and contrast; the total pollution of soils increased by a factor of 1.7 for the 16-year period. The most contrast technogenic anomaly of HMs with $Z_{c}$ about 48 in its center was formed in the northwest under the influence of emissions from the large industrial zone "Sokolinaya Gora" and Shosse Entuziastov Highway. Several anomalies along the Moscow Ring Road (MKAD at Figure 1) which were poorly expressed in 1989 became larger with maximum $Z_{c} 32-40$. Southeast anomaly of HMs in soils also became more pronounced, up to $Z_{c} 48$. Thus, the pollution level in anomalies has changed from the medium to high.

In 2010 a further increase in the areas and intensity of HM anomalies was observed. The northwest anomaly with the total index of soil pollution $Z_{c}$ 48-80 expanded beyond the industrial zone "Sokolinaya Gora" and partly covered residential areas to the south of Shosse Entuziastov Highway. In the center of the district large anomaly with $Z_{c}>$ 100 was formed under the influence of the industrial zone "Perovo" and district heating station (DHS) "Perovskaya." In the southeast part of the district technogenic anomaly of HMs was extended to the east while the $Z_{c}$ indicator increased up to 50-70. It is the result of emissions of recently constructed incineration plant near the settlement of Rudnevo.

Growing contamination of urban soils with HMs is caused not only by an increase in emissions from industry and transport in particular, but also by a change in absorption capacity of the soils. Anthropogenic transformation of the physical and chemical properties of the soils leads to the formation of complex physical and chemical barriers. They arise as a result of precipitation of carbonate construction dust enriched by fine particles, application of soil peat compost mixtures with a high content of humic substances for planting of greenery as well as flooding and soil sealing which alters its gas and redox regimes. The HM accumulation on these man-made barriers is not necessarily accompanied by a reduction in their mobility; analysis of mobile forms of HMs showed that their precipitation from the atmosphere exceeds the speed of their washout from topsoils [28].

3.4. Trends of HM Accumulation in Topsoils and Snow Cover. Tendencies of HM accumulation in the urban soils were evaluated for two periods: 1989-2005 and 2005-2010 by calculation of average annual growth of HM content in the topsoils (Table 3) which differ considerably depending on the type of land use (Figure 4).

From 1989 to 2005 the growth of HM content in soils of the Eastern district was relatively small. The maximum absolute increase was inherent of Mn $(4.4 \mathrm{mg} / \mathrm{kg}$ per year) $>\mathrm{Pb}(3.1)>\mathrm{Zn}(2.8)>\mathrm{Cu}(1.6)>\mathrm{Cr}(0.64)$. Thus, the relative rate was the greatest for $\mathrm{Pb}, \mathrm{Co}, \mathrm{Cu}, \mathrm{Ni}$, and $\mathrm{Cr}(0.07-$ $0.03 \%$ per year) in the soils of industrial zones and near highways, old low-rise residential quarters, and agricultural areas (Figure 4).

In 2005-2010, the rates of HM accumulation in the soils increased and became more differentiated among the landuse zones (Figure 4). Depending on the average annual values HMs form the following sequence: $\mathrm{Cr}(13.1 \mathrm{mg} / \mathrm{kg}$ per year $)>$ $\mathrm{Mn}(3.8)>\mathrm{Ni}(2.2)>\mathrm{Zn}(1.2)>\mathrm{Co}(0.9)$. Cr, Cd, Co, and $\mathrm{Ni}$ had the maximum relative rate of growth (up to $0.5-1.0 \%$ ), in comparison with the previous period it increased by tens times (Table 2). The content of $\mathrm{Pb}, \mathrm{Cs}$, and $\mathrm{Cu}$ significantly decreased showing negative values of the annual rate mainly owing to soil reclamation.

Uneven distribution of HM accumulation rates within the territory of the district is well seen on Figure 4. Cr and Cd show the overall growth, especially in less polluted zones (recreational, agricultural, and new residential areas), while $\mathrm{Pb}$ and $\mathrm{Zn}$ dissipate in the soils of industrial zones and highways, old low-rise residential and agricultural areas. 

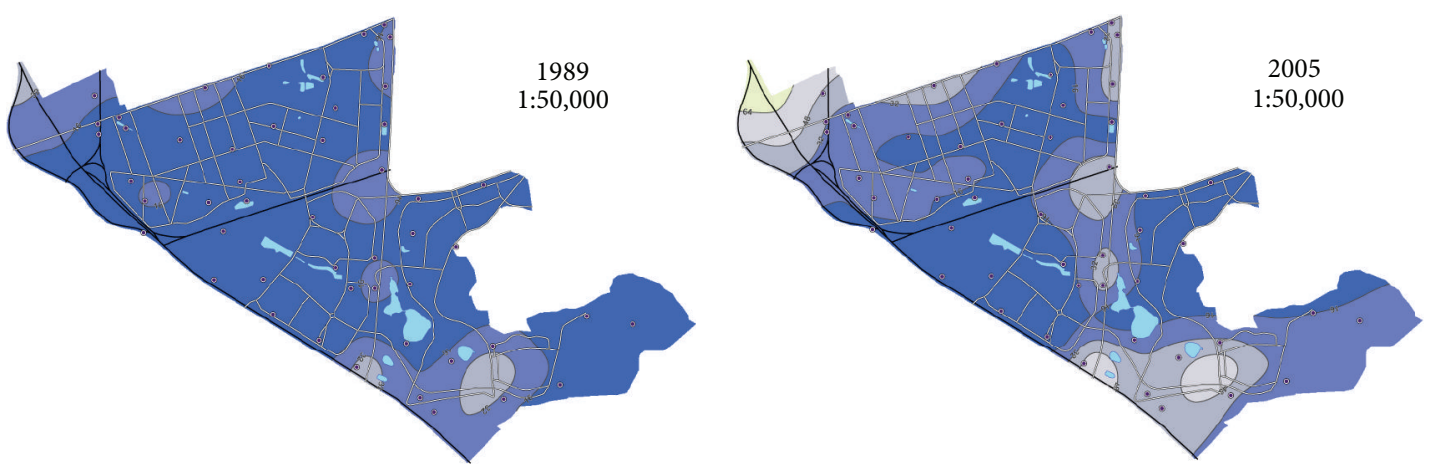

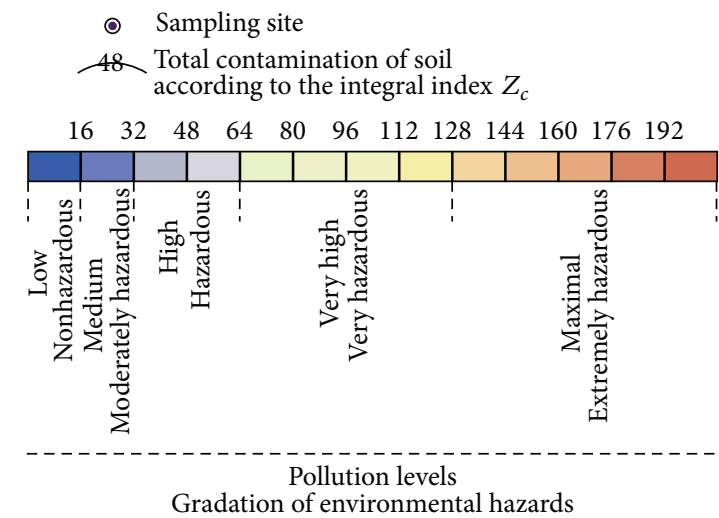

(a)

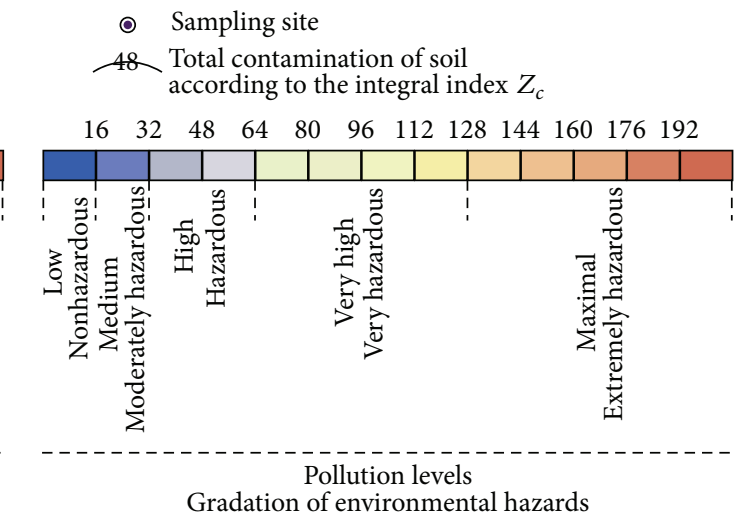

(b)
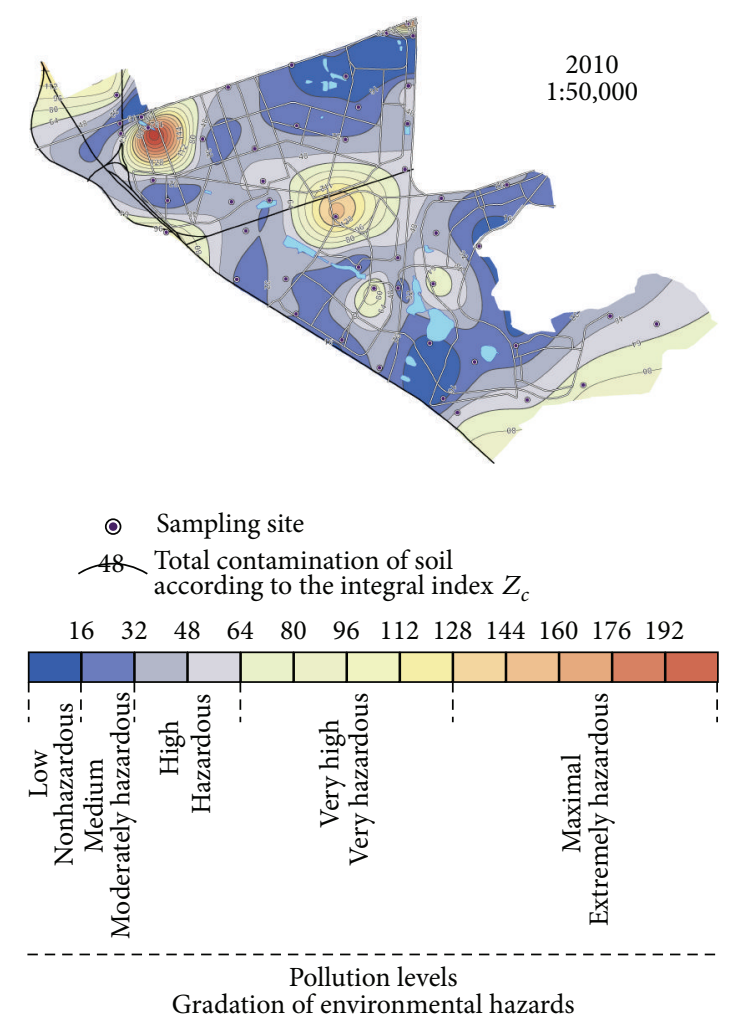

(c)

FIGURE 3: Total technogenic anomalies of HMs (according to $Z_{c}$ index) in topsoils of the Eastern district of Moscow in 1989, 2005 , and 2010. 

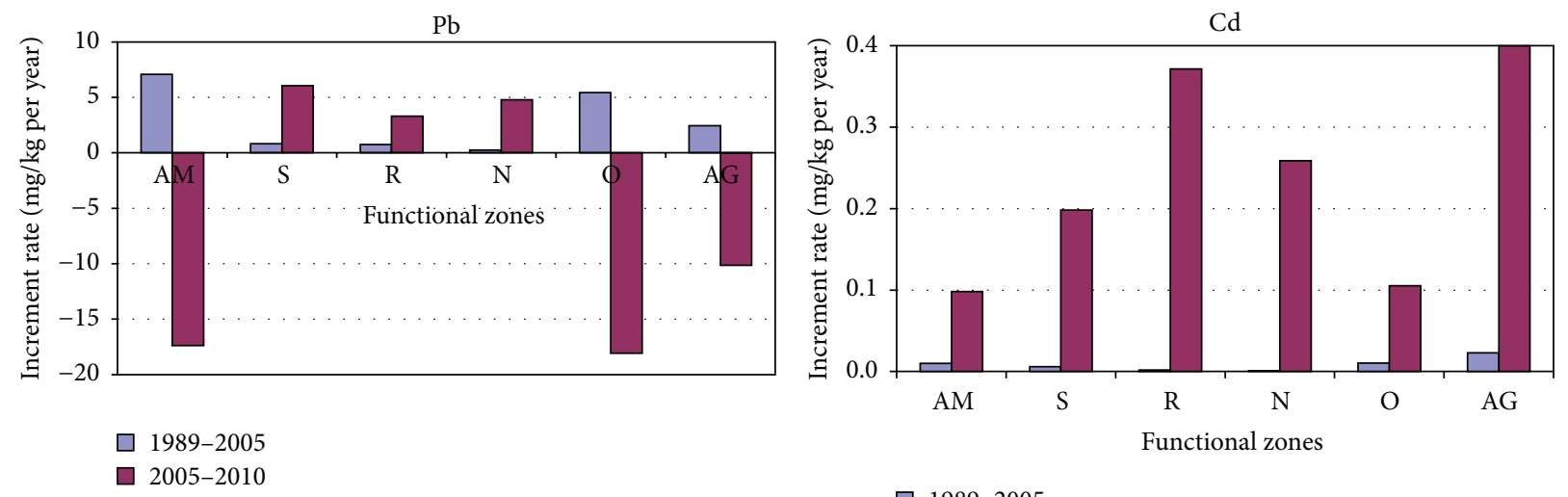

$$
\begin{aligned}
& \square \quad 1989-2005 \\
& \square \quad 2005-2010
\end{aligned}
$$
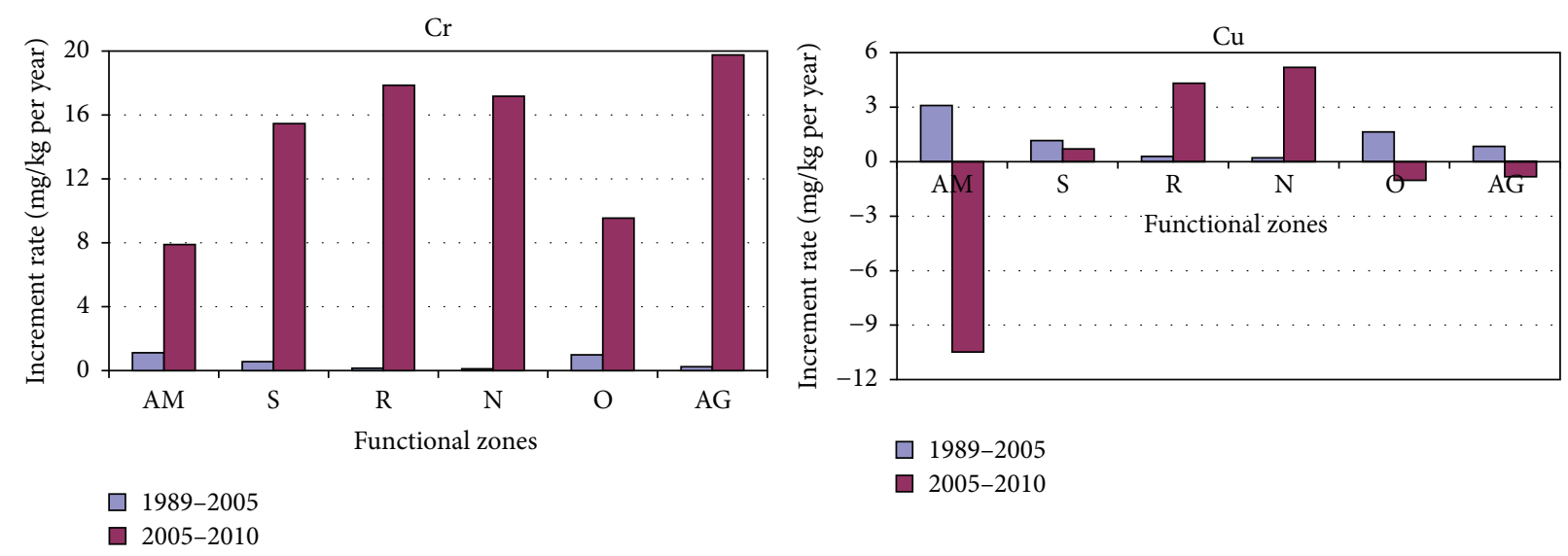

Figure 4: Average increase or reduction of the content of $\mathrm{Pb}, \mathrm{Cd}, \mathrm{Zn}$, and $\mathrm{Cr}$ in the topsoils of different land-use zones in the Eastern district of Moscow for two periods of observations (1989-2005 and 2005-2010). Symbols of land-use zones are given in Table 2.

\begin{tabular}{|c|c|c|c|c|c|c|c|c|}
\hline \multirow[b]{2}{*}{ Observation year } & \multicolumn{8}{|c|}{ Average values of total index of pollution $Z_{c}$ in soils of the land-use zones } \\
\hline & Highways & Industrial & $\begin{array}{c}\text { Medium-rise } \\
\text { residential }\end{array}$ & $\begin{array}{l}\text { High-rise } \\
\text { residential }\end{array}$ & Recreational & $\begin{array}{l}\text { Low-rise } \\
\text { residential }\end{array}$ & Agricultural & $\begin{array}{c}\text { Total for the } \\
\text { district }\end{array}$ \\
\hline 1989 & \multicolumn{2}{|c|}{15.6} & 6.3 & 2.9 & 3.5 & 13.2 & 10.4 & 9.02 \\
\hline 2005 & \multicolumn{2}{|c|}{33.4} & 10.3 & 3.7 & 5.0 & 25.5 & 17.2 & 17.3 \\
\hline 2010 & 17.9 & 28.3 & 20.4 & 15.4 & 17.9 & 18.6 & 22.9 & 19.4 \\
\hline
\end{tabular}

TABLE 4: Long-term dynamics of total HM pollution of soils in the Eastern district of Moscow depending on the type of their use.

The dynamics of soil pollution was compared with the distribution of HMs in the snow. The snow cover reflects actual state of the environment while the soil represents more stable long-term pollution. Joint analysis of snow and soil geochemical maps allows identification of the areas of actual, permanent, and relict pollution. The relict technogenic anomalies occur only in soil cover, modern ones, only in snow, and permanent ones in snow and soils simultaneously [25]. The snow pollution with HMs in the Eastern district of Moscow was defined using the integral index of immission $Z_{d}$ [29]. It characterizes both the composition and amount of dust which accumulates in snow. Overlay of the maps of $Z_{c}$ and $Z_{d}$ integral indices resulted in the identification of permanent anomalies within the major part of the district (Figure 5). In the center of the area a relict anomaly was formed as a result of elimination and reprofiling of the stationary sources of emissions. On the north, along the Shosse Entuziastov Highway a modern anomaly of HMs was discovered in the vicinity of Terletskiy park.

3.5. Assessment of Environmental State of Urban Soils. The analysis of average zonal values of the total indicator of pollution $Z_{c}$ (Table 4 ) showed that in 1989 the most part of the territory under study was characterized by a low level of HM pollution. The average value of $Z_{c}$ was only 9.0 that indicates harmless ecological condition of soils. $Z_{c}$ values exceeded this level only in 10 of 49 sampling sites (i.e., 20.4\%), mainly in the industrial zones and near highways.

In 2005 much less sampling points showed $Z_{c}$ values < 16 (31 of 52, i.e., 59.6\%). Moreover, 14 points (26.9\%) shifted 


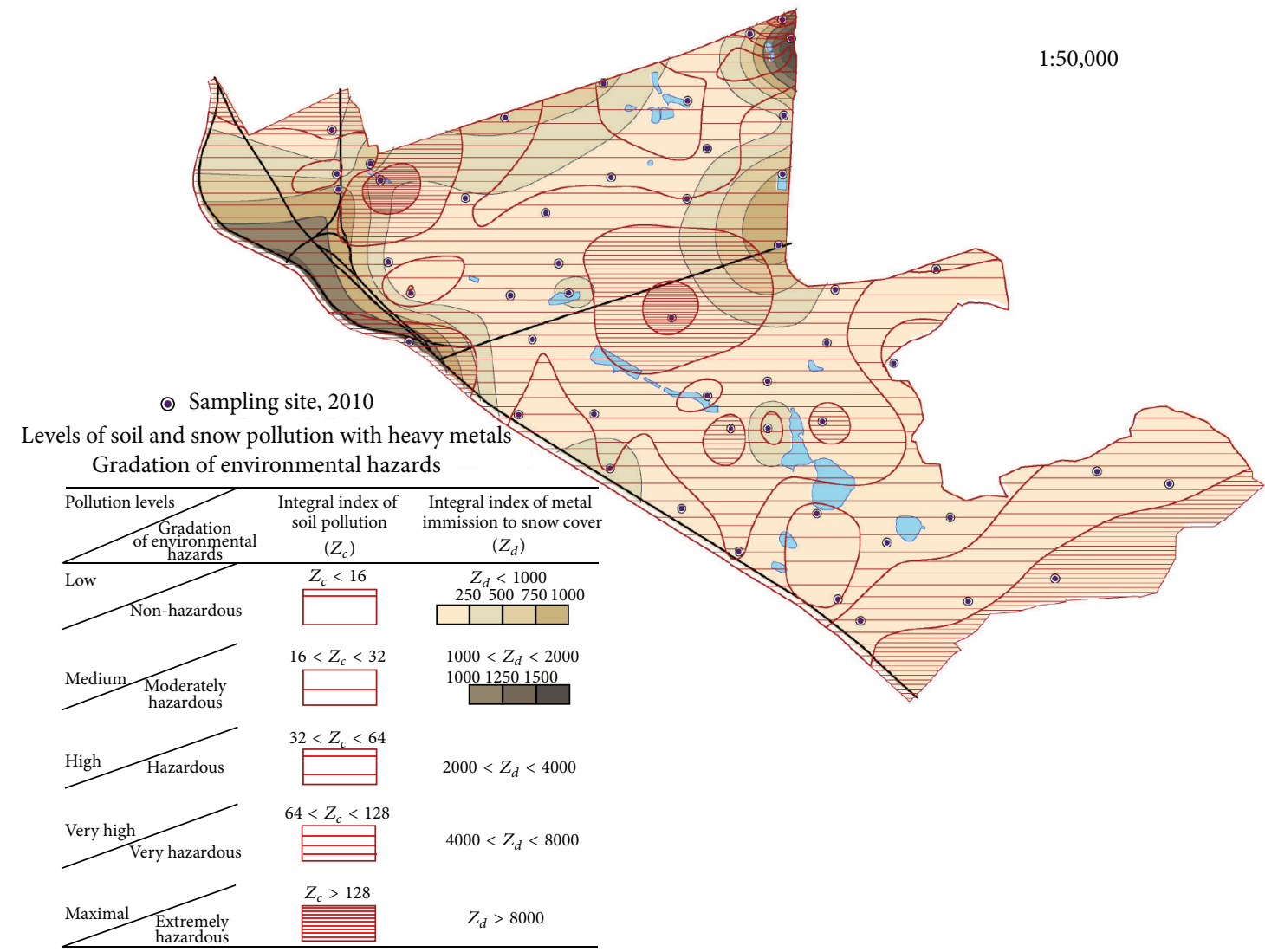

FIGURE 5: Location of areas of actual, permanent, and relict pollution in the Eastern district of Moscow according to anomalies in soils and snow cover.

TABLE 5: Clarks in the lithosphere [15] and the average contents of $\mathrm{Pb}, \mathrm{Zn}, \mathrm{Cr}$, and $\mathrm{Ni}$ in soils (mg/kg) of the various cities of the world (compiled by the authors according to [16-24] and to own data for the Eastern district of Moscow, 2010).

\begin{tabular}{|c|c|c|c|c|c|c|c|c|c|c|c|c|c|}
\hline $\mathrm{HM}$ & $\begin{array}{c}\text { Lithosphere } \\
\text { clark }\end{array}$ & Stockholm & Madrid & Seville & Berlin & Hamburg & London & $\begin{array}{l}\text { Hong } \\
\text { Kong }\end{array}$ & Palermo & Naples & Belgrade & $\begin{array}{c}\mathrm{Da} \\
\text { Nang }\end{array}$ & $\begin{array}{c}\text { Moscow, } \\
\text { Eastern } \\
\text { district }\end{array}$ \\
\hline $\mathrm{Pb}$ & 16 & 101 & 161 & 161 & 119 & 218 & 294 & 93.4 & 253 & 262 & 55.5 & 20.0 & 61.8 \\
\hline $\mathrm{Zn}$ & 83 & 171 & 210 & 107 & 243 & 516 & 183 & 168 & 151 & 251 & 118 & 142 & 189 \\
\hline $\mathrm{Cr}$ & 83 & 34.0 & 74.7 & 42.8 & 35.0 & 95.4 & - & $<40.0$ & 39.0 & 74.0 & 32.1 & 92.2 & 100 \\
\hline $\mathrm{Ni}$ & 58 & 12.8 & 14.1 & 23.5 & 10.7 & 62.5 & - & $<20.0$ & 19.1 & - & 68.0 & 22.6 & 30.6 \\
\hline
\end{tabular}

to medium and 7 points $(13.5 \%)$ to high level of pollution. Average $Z_{c}$ value for the district was 17.3 that corresponds to medium level of HM pollution of soils. There were only three land-use zones with low level of soil contamination, residential zones with medium- and high-rise buildings, and recreational zone (Table 4). In 2005 soils of the residential low-rise zone and agricultural landscapes had medium level of HM pollution, and those of highways and industrial zones had high one.

In 2010 the average $Z_{c}$ value for the district increased up to 19.4. In contrast to the decrease of soil pollution level for highways, industrial and residential zones with low-rise buildings, a significant increase of HM pollution occurred in recreational, agricultural, and residential high-rise zones.
Thus it is only in the latter zone where the level of soil contamination corresponds to harmless category; other zones are moderately polluted $\left(Z_{c} 17.9-28.3\right)$.

To assess the ecological rank of Moscow in terms of the level of HM accumulation in soils among the cities of the world, we compared the average contents of four most common $\mathrm{HMs}$ ( $\mathrm{Pb} \mathrm{Zn,} \mathrm{Cr}$, and $\mathrm{Ni}$ ) in the soils of large and capital cities of several countries with their values in the soils of the Eastern district of Moscow. Soils of the large cities of the world have rather high average HM concentrations (Table 5) comparable to Moscow quantities, especially $\mathrm{Pb}$ and $\mathrm{Zn}$. Most intensive accumulation of $\mathrm{Pb}$ is typical for the soils of London, Naples, Palermo, and Hamburg, while that of $\mathrm{Zn}$ is typical for the soils of Hamburg, Naples, Berlin, and 
Madrid. The contents of $\mathrm{Cr}$ and $\mathrm{Ni}$ are below their clarks in the lithosphere; the minimum values are observed in the soils of Madrid, Berlin, Palermo, and Stockholm. So, according to 2010 data, soils of the Eastern district of Moscow do not show particularly high levels of HM accumulation. The average content of $\mathrm{Pb}$ in the topsoils of the district is close to its values in the soils of Belgrade and that of $\mathrm{Zn}$ is close to its values in the soils of Stockholm and London. The same levels of the content of $\mathrm{Cr}$, as in soils of the Eastern district, are recorded in Palermo and Hamburg, and that of $\mathrm{Ni}$ is recorded in Seville and Palermo.

\section{Conclusions}

Soils of the Eastern district of Moscow show the gradual increase of $\mathrm{HM}$ pollution levels. Among them $\mathrm{Pb}$ and $\mathrm{Zn}$ are the leaders with enrichment factors EF 3.7-9.9. In $2010 \mathrm{Cd}$ joined them (EF 4.7); the intensive growth of its content is caused by its presence in the motor vehicle emissions as well as by application of mineral and organic fertilizers and sewage sludge containing $\mathrm{Cd}$ as an admixture. Over the last 5 years the contents of $\mathrm{Pb}$ and $\mathrm{Cu}$ in soils of the district decreased owing to the soil reclamation and adding uncontaminated material, the exclusion of leaded gasoline as a fuel for vehicles, and also conversion and closing a number of hazardous industrial enterprises which emit these metals.

In 1989-2005 the annual increase of HM concentrations in soils of the Eastern district was rather low. $\mathrm{Pb}$ and $\mathrm{Cu}$ demonstrated the maximum rates of increase $(0.08$ and $0.04 \%$ per year, resp.). In 2005-2010 rates of the annual increase of HM concentrations in soils were higher, with more pronounced differentiation in particular land-use zones. $\mathrm{Cr}$, $\mathrm{Cd}, \mathrm{Co}$, and $\mathrm{Ni}$ had the maximum rates of increase $(1.0-0.45 \%$ per year). The contents of $\mathrm{Pb}$ and $\mathrm{Cu}$ in the soils of industrial zones and highways, agricultural, and old residential areas went down. Nevertheless, these zones still have the highest contents and the widest range of elements pollutants.

At present, a medium total pollution level is common for the soils of the Eastern district, with the $Z_{c}$ index reaching 28.3 in the industrial zone. The priority contaminants are $\mathrm{Pb}$, $\mathrm{Zn}$, and $\mathrm{Cd}$. The maximum level of $\mathrm{Pb}$ and $\mathrm{Zn}$ concentrations (114 and $286 \mathrm{mg} / \mathrm{kg}$, resp.) in topsoils has been revealed in the industrial zone, while that of $\mathrm{Cd}(3.7 \mathrm{mg} / \mathrm{kg})$ has been revealed in the recreational zone.

To represent the stages of development of the technogenic multielemental anomalies in urban soils maps of a total index of pollution $Z_{c}$ were compiled for particular years of the 21-year period of observations. Their analysis revealed a significant increase of the contrast and the area of HM anomalies in recent years, which could be attributed to the growth of the total amount of industrial and motor transport emissions and change in absorption capacity of the urban soils.

\section{Conflict of Interests}

The authors declare that there is no conflict of interests regarding the publication of this paper.

\section{Acknowledgments}

Field and chemical works were supported by the Russian Geographic Society and the Russian Foundation for Basic Research (Project no. 13-05-41191), and analysis and interpretation of geochemical data were accomplished with the financial support of the Russian Scientific Foundation (Project no. 14-27-00083). The authors thank Dr. D. V. Vlasov and Mrs. G. L. Shinkareva who took part in the field investigations. Dr. T. S. Khaybrakhmanov is much appreciated for the geochemical maps he compiled.

\section{References}

[1] E. M. Nikiforova and G. G. Lazukova, "Moscow. Perovo District. Plain landscapes," in Ecogeochemistry of Urban Landscapes, N. S. Kasimov, Ed., pp. 57-90, Moscow University Publishing House, Moscow, Russia, 1995 (Russian).

[2] S. B. Samaev, L. S. Sokolov, and A. S. Panteleev, "Soil pollution caused by motor traffic in Moscow," in Automotive Complex and Ecological Safety, pp. 266-270, Prima-Press-M, Moscow, Russia, 1999 (Russian).

[3] Yu. N. Nikolaev, T. V. Shestakova, V. V. Nefed'ev et al., Assessment of Geochemical Contamination in the Losinyi Ostrov National Park, Prima-Press-M, Moscow, Russia, 2000 (Russian).

[4] Kh. G. Yakubov, Environmental Monitoring of Plantations in Moscow, Stagirit-N, Moscow, Russia, 2005 (Russian).

[5] E. M. Nikiforova and N. E. Kosheleva, "Dynamics of contamination of urban soils with lead in the Eastern district of Moscow," Eurasian Soil Science, vol. 40, no. 8, pp. 880-892, 2007.

[6] E. M. Nikiforova and N. E. Kosheleva, "Fractional composition of lead compounds in soils of Moscow and Moscow region," Eurasian Soil Science, vol. 42, no. 8, pp. 874-884, 2009.

[7] O. V. Plyaskina and D. V. Ladonin, "Heavy metal pollution of urban soils," Eurasian Soil Science, vol. 42, no. 7, pp. 816-823, 2009.

[8] I. A. Avessalomova, "Landscapes of Meshchera lowplain," in Landscape-Geochemical Principles of Background Monitoring of Natural Environment, M. A. Glazovskaya and N. S. Kasimov, Eds., pp. 79-90, Nauka, Moscow, Russia, 1989 (Russian).

[9] T. V. Prokofyeva, I. A. Martynenko, and F. A. Ivannikov, "Classification of Moscow soils and parent materials and its possible inclusion in the classification system of Russian soils," Eurasian Soil Science, vol. 44, no. 5, pp. 561-571, 2011.

[10] N. I. Ivanov, Ed., Engineering Ecology and Environmental Management, Logos, Moscow, Russia, 2002 (Russian).

[11] V. R. Bityukova and R. Argenbrayt, "Regional peculiarities of modern ecological situation in Moscow: premises, contemporary tendencies, prospect," Eurasian Geography and Economics, no. 4, pp. 14-31, 2002.

[12] E. M. Nikiforova, N. E. Kosheleva, I. A. Labutina, and T. S. Khaybrakhmanov, "Geoinformation landscape-geochemical mapping of city territories (the case study of Eastern District of Moscow)," Journal of Civil Engineering and Science, vol. 3, no. 3, pp. 142-151, 2014.

[13] C. C. Johnston, A. Demetriades, J. Locutra, and R. T. Ottesen, Mapping the Chemical Environment of Urban Areas, John Wiley \& Sons, Chichester, UK, 2011.

[14] N. S. Kasimov, V. R. Bityukova, A. V. Kislov et al., "Problems of urban geochemistry," Exploration and Conservation of Mineral Resources, no. 7, pp. 8-13, 2012 (Russian). 
[15] A. P. Vinogradov, "Average content of chemical elements in the main types of igneous rocks," Geochemistry, no. 7, pp. 555-572, 1962 (Russian).

[16] P. Tume, J. Bech, B. Sepulveda, L. Tume, and J. Bech, "Concentrations of heavy metals in urban soils of Talcahuano (Chile): a preliminary study," Environmental Monitoring and Assessment, vol. 140, no. 1-3, pp. 91-98, 2008.

[17] M. Linde, H. Bengtsson, and I. Oborn, "Concentrations and pools of heavy metals in urban soils in Stockholm, Sweden," Water, Air, \& Soil Pollution: Focus, vol. 1, pp. 83-101, 2001.

[18] H. T. T. Thuy, H. J. Tobschall, and P. V. An, "Distribution of heavy metals in urban soils-a case study of Danang-Hoian Area (Vietnam)," Environmental Geology, vol. 39, no. 6, pp. 603$610,2000$.

[19] X. Li, C.-S. Poon, and P. S. Liu, "Heavy metal contamination of urban soils and street dusts in Hong Kong," Applied Geochemistry, vol. 16, no. 11-12, pp. 1361-1368, 2001.

[20] M. Birke and U. Rauch, "Urban geochemistry: investigations in the Berlin metropolitan area," Environmental Geochemistry and Health, vol. 22, no. 3, pp. 233-248, 2000.

[21] M. Imperato, P. Adamo, D. Naimo, M. Arienzo, D. Stanzione, and P. Violante, "Spatial distribution of heavy metals in urban soils of Naples city (Italy)," Environmental Pollution, vol. 124, no. 2, pp. 247-256, 2003.

[22] L. Madrid, E. Diaz-Barrientos, E. Ruiz-Cortés et al., "Variability in concentrations of potentially toxic elements in urban parks from six European cities," Journal of Environmental Monitoring, vol. 8, no. 11, pp. 1158-1165, 2006.

[23] D. Crnković, M. Ristić, and D. Antonović, "Distribution of heavy metals and arsenic in soils of Belgrade (Serbia and Montenegro)," Soil \& Sediment Contamination, vol. 15, no. 6, pp. 581-589, 2006.

[24] F. Ajmone-Marsan and M. Biasioli, "Trace elements in soils of urban areas," Water, Air, \& Soil Pollution, vol. 213, no. 1, pp. 121$143,2010$.

[25] Yu. E. Saet, B. A. Revich, E. P. Yanin et al., Geochemistry of the Environment, Nedra, Moscow, Russia, 1990 (Russian).

[26] N. S. Kasimov, N. E. Kosheleva, O. I. Sorokina, S. N. Bazha, P. D. Gunin, and S. Enkh-Amgalan, "Ecological-geochemical state of soils in Ulaanbaatar (Mongolia)," Eurasian Soil Science, vol. 44, no. 7, pp. 709-721, 2011.

[27] A. I. Perel'man, Geochemistry of Elements in the Hypergenesis Zone, Nedra, Moscow, Russia, 1972 (Russian).

[28] N. E. Kosheleva, N. S. Kasimov, and D. V. Vlasov, "Factors of the accumulation of heavy metals and metalloids at geochemical barriers in urban soils," Eurasian Soil Science, vol. 48, no. 5, pp. 476-492, 2015.

[29] N. S. Kasimov, N. E. Kosheleva, D. V. Vlasov, and E. V. Terskaya, "Geochemistry of snow cover in the Eastern District of Moscow," Moscow University Vestnik. Series 5. Geography, no. 4, pp. 14-25, 2012 (Russian). 

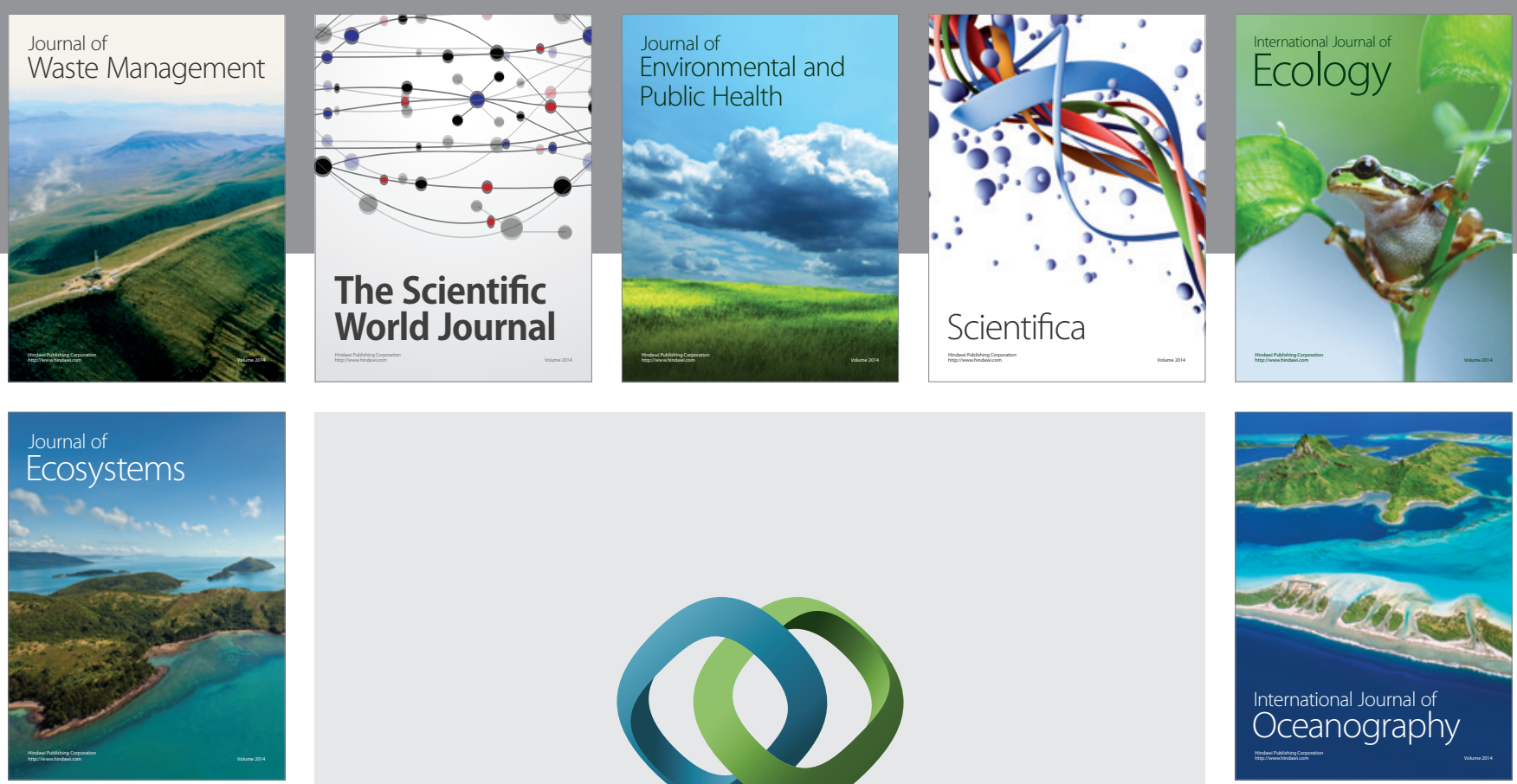

The Scientific World Journal
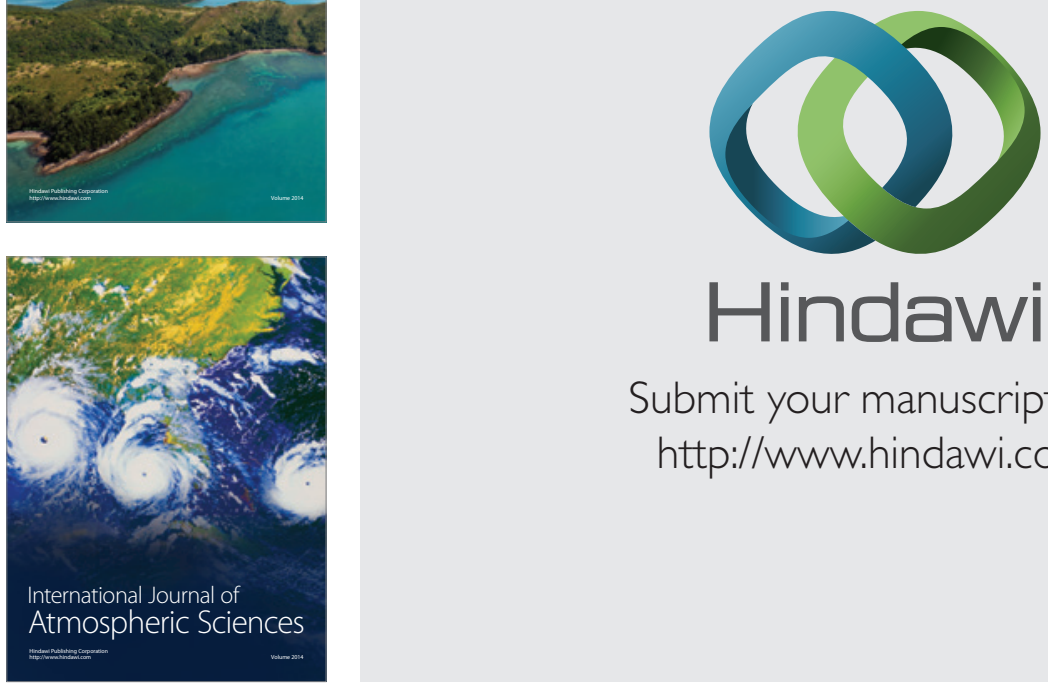

\section{Hindawi}

Submit your manuscripts at

http://www.hindawi.com
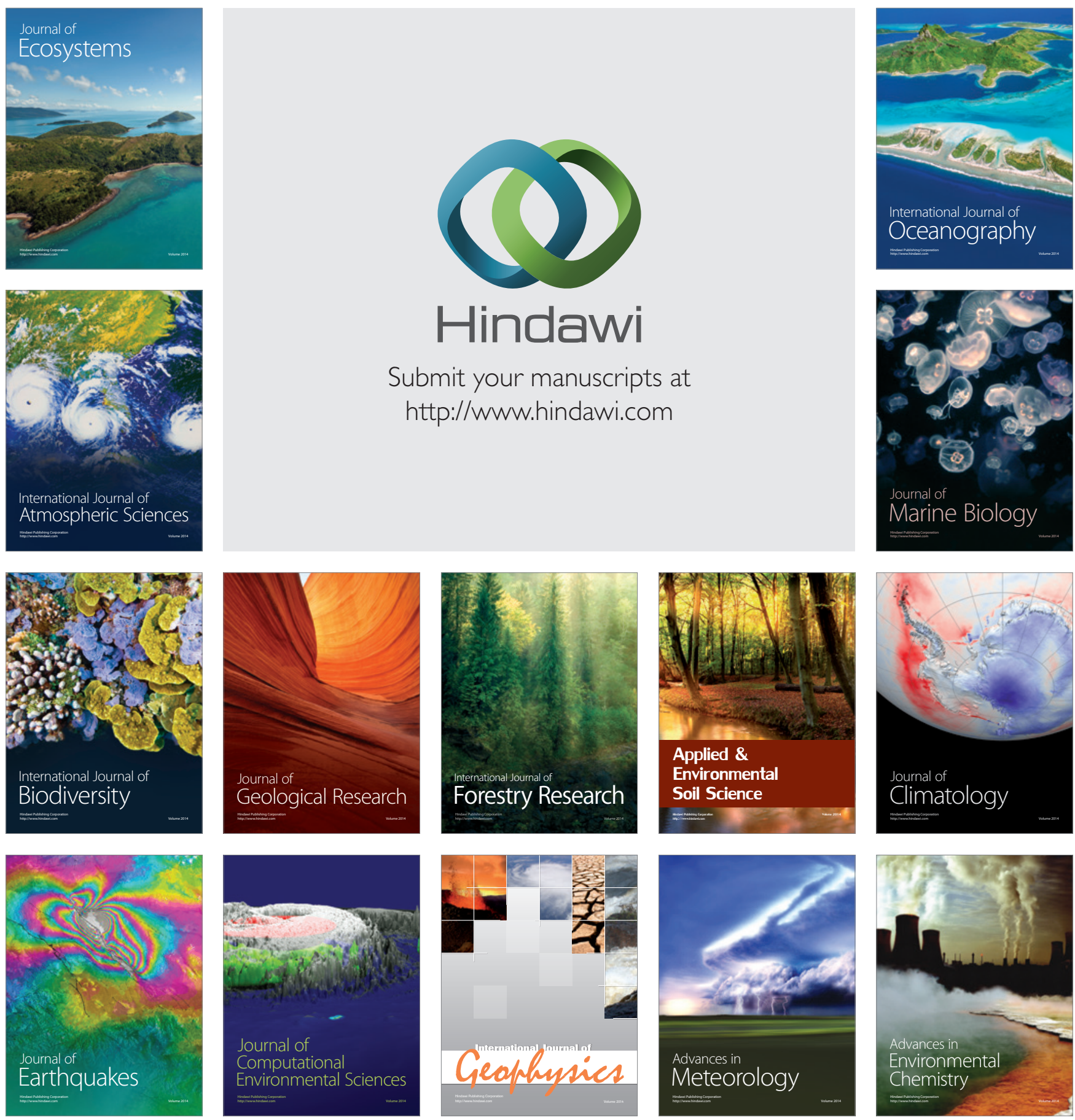